Journal Club

Editor's Note: These short reviews of a recent paper in the Journal, written exclusively by graduate students or postdoctoral fellows, are intended to mimic the journal clubs that exist in your own departments or institutions. For more information on the format and purpose of the Journal Club, please see http://www.jneurosci.org/misc/ifa_features.shtml.

\title{
A Molecular Switch for Induction of Long-Term Depression of Corticostriatal Transmission
}

\author{
Mazen A. Kheirbek \\ Committee on Neurobiology, University of Chicago, Chicago, Illinois 60637 \\ Review of Adermark and Lovinger (http://www.jneurosci.org/cgi/content/full/27/25/6781)
}

Long-term modification of synaptic transmission at corticostriatal synapses is implicated in voluntary motor control, reward-based learning, and habit formation (Reynolds and Wickens, 2002; Yin and Knowlton, 2006). Unlike many excitatory synapses in the brain that are potentiated by high-frequency afferent stimulation, repeated activation of glutamatergic afferents in the presence of tonic levels of dopamine induces long-term depression (HFS-LTD) of synapses on medium spiny neurons (MSNs) in the dorsolateral striatum. HFS-LTD requires dopamine $\mathrm{D}_{2}$ receptor activation, high levels of intracellular calcium, and retrograde release of endocannabinoids that activate presynaptic $\mathrm{CB}_{1}$ receptors. A recent study by Adermark and Lovinger (2007) in The Journal of Neuroscience provides strong evidence that activation of L-type calcium channels may be the molecular switch in this signaling pathway, bypassing dopaminedependent mechanisms to induce corticostriatal LTD (Fig. 1).

In their first experiment, Adermark and Lovinger (2007) show that LTD can be induced with only modest presynaptic activity and modest postsynaptic depolarization if there is a strong activation of L-type calcium channels [Adermark and Lovinger (2007), their Fig. $1 A$ (http://www.jneurosci.org/cgi/

Received June 28, 2007; revised July 27, 2007; accepted July 28, 2007. Correspondence should be addressed to Mazen A. Kheirbek at the above address. E-mail:mazen@uchicago.edu.

DOI:10.1523/JNEUROSCI.2938-07.2007

Copyright $\odot$ 2007 Society for Neuroscience $\quad$ 0270-6474/07/279824-02\$15.00/0
content/full/27/25/6781/F1)]. Specifically, coincident depolarization of the postsynaptic cell to $-50 \mathrm{mV}$ and paired-pulse afferent stimulation in the presence of the L-type calcium channel activator 2,5-dimethyl-4-[2(phenylmethyl)benzoyl]-1 H-pyrrole-3-carboxylic acid methylester (FPL64176) induced a dose-dependent decrease in EPSC amplitude recorded from striatal medium spiny neurons (FPL-LTD) [Adermark and Lovinger (2007), their Fig. $1 B$ (http:// www.jneurosci.org/cgi/content/full/27/25/ $6781 / F 1)]$. FPL also produced a gradual increase in the paired-pulse ratio, suggesting that synaptic depression was attributable to a reduction in presynaptic release of neurotransmitter [Adermark and Lovinger (2007), their Fig. $1 E$ (http://www.jneurosci. org/cgi/content/full/27/25/6781/F1)].

To get to the molecular mechanisms, the authors examined whether the processes involved in HFS-LTD also play a role in FPL-LTD. Like HFS-LTD, FPLLTD required postsynaptic depolarization, increased intracellular calcium, and activated L-type calcium channels because hyperpolarization, intracellular perfusion of BAPTA, and blockade of L-type calcium channels blocked FLPLTD [Adermark and Lovinger (2007), their Fig. 2 (http://www.jneurosci.org/cgi/ content/full/27/25/6781/F2)]. Furthermore, blockade of $\mathrm{CB}_{1}$ receptors blocked induction of FLP-LTD [Adermark and Lovinger (2007), their Fig. 3 (http://www. jneurosci.org/cgi/content/full/27/25/6781/ F3)]. Finally, FLP-LTD could not be in- duced in the absence of presynaptic stimulation [Adermark and Lovinger (2007), their Fig. 5 (http://www.jneurosci. org/cgi/content/full/27/25/6781/F5)].

Despite the shared characteristics between HFS-LTD and FPL-LTD, FPL-LTD has a number of interesting differences. Metabotropic glutamate receptor (mGluR) activation has been implicated in corticostriatal LTD because of the positive coupling to the phospholipase C (PLC) pathway and release of intracellular stores of calcium. However, blockade of $\mathrm{mGluR}_{1}$ receptors failed to block FPLLTD, suggesting that strong activation of L-type calcium channels can override the requirement for PLC-dependent calcium release. The PLC blocker U73122 [1-[6((17 $\beta$-3-methoxyestra-1,3,5(10)-trien-17yl)amino)hexyl]-1 $H$ - pyrrole-2,5-dione] also did not block FPL-LTD [Adermark and Lovinger (2007), their Fig. $4 A, B$ (http://www.jneurosci.org/cgi/content/full/ 27/25/6781/F4)]. Blockade or genetic deletion of dopamine $\mathrm{D}_{2}$ receptors causes loss of HFS-LTD (Reynolds and Wickens, 2002). Surprisingly, FPL-LTD was not blocked by the $\mathrm{D}_{2}$ receptor antagonist sulpride [Adermark and Lovinger (2007), their Fig. 4C (http://www.jneurosci.org/ cgi/content/full/27/25/6781/F4)]. These data collectively suggest that activation of L-type calcium channels may be the final common pathway for LTD induction. Moreover, FPL-LTD occluded subsequent induction of LTD by highfrequency stimulation of cortical afferents 


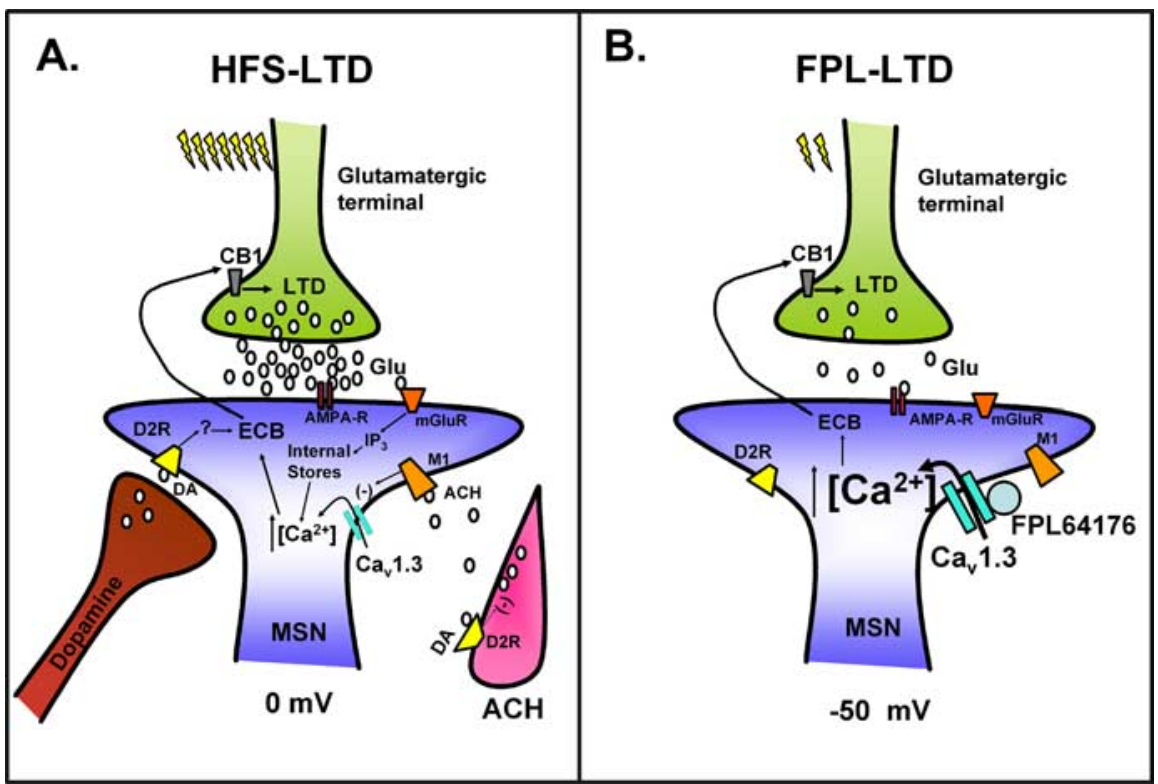

Figure 1. Signaling pathways involved in corticostriatal HFS-LTD and FPL-LTD. A, High-frequency stimulation of cortical afferents with coincident depolarization of the postsynaptic membrane to $0 \mathrm{mV}$ is required for induction of HFS-LTD. In addition, there is a dependence on $D_{2}$ receptors, either on the MSN itself, promoting retrograde endocannabinoid (ECN) release, or on acetylcholine ( $\mathrm{ACH}$ )-positive interneurons by reducing $\mathrm{ACH}$ tone, thus reducing the $\mathrm{M}_{1}$ muscarinic receptor-mediated inhibition of $\mathrm{Ca}_{\mathrm{v}} 1.3$ channels (Wang et al., 2006; Kreitzer and Malenka, 2007). Influx of calcium through voltage-gated $\mathrm{Ca}_{\mathrm{v}} 1.3$ type channels or by release from intracellular stores by an mGluR-dependent inositol triphosphate mechanism can also promote the retrograde release of ECNs. Activation of presynaptic $\mathrm{CB}_{1}$ receptor induces a depression in glutamate release. $\boldsymbol{B}$, In FPL-LTD, strong activation of $\mathrm{Ca}_{v} 1.3$ channels can induce large increases in intracellular calcium, bypassing dopamine- and mGluR-dependent mechanisms, promoting the retrograde release of ECNs and depression of glutamate release. DA, Dopamine; AMPA-R, AMPA receptor; ECB, endocannabinoid.

[Adermark and Lovinger (2007), their Fig. $4 F$ (http://www.jneurosci.org/cgi/ content/full/27/25/6781/F4)], indicating that FPL-LTD and HFS-LTD are mediated by the same pathway.

It is interesting that FLP-LTD is $\mathrm{D}_{2}$ dopamine receptor independent. Dopamine-dependent changes in synaptic efficacy of corticostriatal terminals has been receptor activation, a $D_{1}$-type receptormediated pathway also has been implicated in HFS-LTD (Centonze et al., 2003). In addition, pharmacological rescue of corticostriatal LTD in mouse models of Parkinson's disease with $\mathrm{CB}_{1}$ and $\mathrm{D}_{2}$ receptor agonists can rescue the motor impairments associated with dopamine depletion (Kreitzer and Malenka, 2007). The next important experiment will be to test the therapeutic potential of FPL64176 by examining whether FPL-LTD is intact in dopamine-depleted animals, and if so, whether FPL64176 can rescue motor deficits in animal models of Parkinson's disease.

\section{References}

Adermark L, Lovinger DM (2007) Combined activation of L-type $\mathrm{Ca}^{2+}$ channels and synaptic transmission is sufficient to induce striatal longterm depression. J Neurosci 27:6781-6787.

Centonze D, Grande C, Saulle E, Martin AB, Gubellini P, Pavon N, Pisani A, Bernardi G, Moratalla R, Calabresi P (2003) Distinct roles of D1 and D5 dopamine receptors in motor activity and striatal synaptic plasticity. J Neurosci 23:8506-8512.

Kreitzer AC, Malenka RC (2007) Endocannabinoid-mediated rescue of striatal LTD and motor deficits in Parkinson's disease models. Nature 445:643-647.

Reynolds JN, Wickens JR (2002) Dopaminedependent plasticity of corticostriatal synapses. Neural Netw 15:507-521.

Wang Z, Kai L, Day M, Ronesi J, Yin HH, Ding J, Tkatch T, Lovinger DM, Surmeier DJ (2006) Dopaminergic control of corticostriatal longterm synaptic depression in medium spiny neurons is mediated by cholinergic interneurons. Neuron 50:443-452.

Yin HH, Knowlton BJ (2006) The role of the basal ganglia in habit formation. Nat Rev Neurosci 7:464-476. 